Article

\title{
Study on the Relationship between Land Transport and Economic Growth in Xinjiang
}

\author{
Jingxin Sun ${ }^{1,2} \mathbb{1}$, Zhinong $\mathrm{Li}^{1,3, *}$, Jiaqiang Lei ${ }^{1, *}$, Dexiong Teng ${ }^{4}$ and Shengyu $\mathrm{Li}^{1}$ \\ 1 National Engineering Technology Research Center for Desert-Oasis Ecological Construction, \\ Xinjiang Institute of Ecology and Geography, Chinese Academy of Sciences, Urumqi 830011, China; \\ mutingcunyu@126.com (J.S.); oasis@ms.xjb.ac.cn (S.L.) \\ 2 University of Chinese Academy of Sciences, Beijing 100000, China \\ 3 Transport Department of Xinjiang Uygur Autonomous Region, Urumqi 830000, China \\ 4 Institute of arid Ecology and Environment, Xinjiang University, Urumqi 830046, China; \\ shadows923@163.com \\ * Correspondence: zhnlee@163.com (Z.L.); desert@ms.xjb.ac.cn (J.L.); Tel.: +86-138-0993-9190 (Z.L.); \\ $+86-131-7980-8310$ (J.L.)
}

Received: 29 November 2017; Accepted: 5 January 2018; Published: 8 January 2018

\begin{abstract}
Xinjiang's land transport network is mainly comprised of highways and railways. Using statistical data from 1985 to 2015, this study applies the Lotka-Volterra model to investigate the competitive interactions among highway transport, railway transport, and the regional economy of Xinjiang. We can draw the following conclusions: First, highway mileage, highway passenger transportation, and railway freight transportation have played a significant role in promoting the development of the national economy in Xinjiang, while the latter has weakened highway passenger transportation and promoted the growth of the added value of transportation industry (AVTI), railway mileage, and railway passenger transportation. Second, highway passenger transportation enhances the development of railway passenger transportation, while railway freight transportation has played the same role in the development of highway freight transportation. Third, the increase in AVTI will increase total population, but both may have a negative impact on the national economy in the short term. Fourth, there is no significant relationship between the economy and transportation investment.
\end{abstract}

Keywords: highway transport; railway transport; Xinjiang; GDP; LV model

\section{Introduction}

In recent years, with the rapid economic development of society, it is increasingly more convenient for people to travel. Travel modes tend to be diversified, but the most common ways to travel are by highway and rail transport. Promoting and influencing the growth of the national economy by fully developing the advantages of highway and rail transport while achieving sustainable development between the transport industry and the national economy have been proven to be hot topics in recent research.

The relationship between the national economy and transportation seems complex because these two parameters form a dynamic system made up of a variety of factors, and these factors are interdependent and interact with each other when the system is operating. The mainstream view in ongoing research is that the national economy and transportation complement each other; transportation is not just a condition of regional development, but also a result of it [1-3]. Some scholars have empirically proven the driving effects of transportation and transportation investment on economic growth. Other research has shown that there is a long-term equilibrium relationship between freight volume and gross domestic product (GDP), and that transportation can promote the development of the whole national economy [4]. With economic development, rapidly expanding markets make the region's economy more closely linked, placing higher demands on transportation. 
Economic development has brought a great deal of financial support to the transportation industry. However, the relationship between economic development and transportation is inconsistent because of geographical conditions, social environments, and national policy changes $[5,6]$.

Mehmet et al. [7] investigates the Granger-causality relationship between income and transportation in EU-15 countries using a panel data set covering the period 1970-2008. Their findings indicate that the dominant type of Granger-causality is bidirectional. Instances of one-way or no Granger-causality were found to correspond with countries with the lowest income per capita ranks in 1970 and/or in 2008. Michael and David [8] test for mutual causality between the growth of road networks and changes in county-level population and employment using a panel data set containing observations of road mileage by type for all Minnesota counties over the period 1988 to 2007. The results indicate that causality runs in both directions between population and local road networks, while no evidence of causality in either direction is found for networks and local employment; these findings are evidence of the weakening influence of road networks on location.

On the other hand, there are some studies that try to explain the economic impact of transportation. For example, through the decomposition of the decoupling index of road freight traffic, Kveiborg and Fosgerau [9] find that the use of large vehicles, larger truckloads, and fewer empty loads are the most important drivers of economic growth. Li et al. [10] found that highway passenger turnover, annual average quality ratings of highways, and the rate of cement highways to administrative villages are the three primary factors that should be focused on in the future. Their findings also show that the development of highway traffic is closely related to the speed of economic development and transportation investment.

With the 'Belt and Road Initiative' proposed in China, in Xinjiang, which is located in the northwest border area, the transportation industry has received increasingly more unprecedented capital investment and technical support. Therefore, the relationship between Xinjiang's economic development and the transportation infrastructure has obvious political implications. Domestic scholars also have done a lot of basic work, which provides a good reference for future research. Feng [11] and $\mathrm{Xu}$ [12] analyzed the contribution of highway transportation to the development of Xinjiang's national economy and Xinjiang production and construction forces. The results showed that highway transportation has a positive effect on the promotion of social employment and economic growth. Zhu [13] studied the relationship between regional transportation and economic development in southern Xinjiang from 1999 to 2009, and predicted that their development trend will change from lagging growth to leading growth between 2010 and 2020 . Zhang et al. [14] found that highway transportation's contribution to Xinjiang's economic growth is on a path of sustained and rapid growth over time, and that railway and aviation transportation contributed more slowly to economic growth.

These studies on transportation and economic development mostly focus on the macro scale, and there is less study of the competition between the national economy and land transport. To systematically investigate the interaction between land transport and Xinjiang's national economy, we suggest a triangular Lotka-Volterra $[15,16]$ competition model for sustainable development (LV-COMSUD). Invented from predator-prey relationship researches, the LV-COMSUD model treats land transportation, GDP and other parameters as dynamic system's components, and examines their interactions applying a set of ordinary differential equations in a general form of competing species. This model provides the advancement and research of a transportation development planning basis and a brand new standpoint. In particular, LV-COMSUD seeks to identify the requisite activities for advancing the coordinated evolution of transportation's distinct modes, and promoting and affecting the national economy together.

\section{Study Area}

Xinjiang is an arid zone that is affected by the temperate continental climate. The features of this wide geographical area include rich reserves of resources, ethnic minorities, and a weak economic foundation [4]. Xinjiang's GDP in 2015 was 932.48 billion, only accounting for 1.4\% of China's GDP. 
In the same area, the GDP of Shanxi Province in the northwest region of China was 1821.26 billion yuan, while Xinjiang was only 51.7\% of its GDP. Xinjiang, as China's Western portal, has 111 border lines in five of eight bordering countries surrounding this region. It is China's gateway to Central Asia, West Asia, Southwest Asia, Europe, and Africa [17]. Xinjiang has played an important role in China's national economic development, social stability, national unity, and national security.

During the "Twelve-Five" period, land transportation in Xinjiang has seen significant development; 250 billion yuan (70 billion for railway and about 180 billion for highways) have been invested in land transportation. By the end of 2015, there were $5789 \mathrm{~km}$ of railway operating in Xinjiang, an increase of $1486 \mathrm{~km}$ compared with the end of the "Eleventh Five-Year". The total distance of highways reached $176,000 \mathrm{~km}$, an increase of 23,000 km compared with the end of the "Eleventh Five-Year" [18].

\section{Materials and Methods}

While the GHRE (GDP-highway transportation-railway transportation-economic indicators of transportation) issues are very complicated, the Lotka-Volterra nonlinear system offers an elementary model, which can be used to capture the dynamic competitive relationships' principal features among them. The proposed LV-COMSUD includes 14 variables that were collected from the Xinjiang Statistical Yearbook from 1985 to 2015(Statistic Bureau of Xinjiang Uygur Autonomous Region). A description of these variables is presented in Table 1 .

A univariate linear model, the ARIMA (autoregressive integrated moving average) model [19], is applied to predict the principal factors from 1985 to 2015, and to supply a benchmark to estimate the LV-COMSUD model's consequences.

To evaluate the forecasting capability of the LV-COMSUD model, forecasting accuracy is examined by calculating the MAPE (mean absolute percentage error) statistic as follows:

$$
\text { MAPE }=\frac{\sum_{\mathrm{i}=1}^{\mathrm{n}}\left|\frac{\left(\mathrm{P}_{\mathrm{i}}-\mathrm{A}_{\mathrm{i}}\right)}{\mathrm{A}_{\mathrm{i}}}\right|}{\mathrm{n} * 100}
$$

where $A_{i}$ is the ith actual value, $P_{i}$, derived from the concurrent Equation (3), is the ith predict value, and $\mathrm{n}$ is the number of forecasts. We conform to Lewis [20] in interpreting the MAPE as a measure of predicted precision, with below $10 \%$ as extremely precise; $10-20 \%$ good; $20-50 \%$ reasonable; and beyond $50 \%$ as inaccurate.

Table 1. Content information of the 14 variables collected.

\begin{tabular}{cccc}
\hline Variables & Description & Variables & Description \\
\hline X1 & Gross Domestic Product (GDP) & X8 & Highway freight turnover (HFT) \\
\hline X2 & Highway passenger volume (HPV) & X9 & Railway freight turnover (RFT) \\
\hline X3 & Railway passenger volume (RPV) & X10 & Highway mileage (HM) \\
\hline X4 & Highway passenger turnover (HPT) & X11 & Railway mileage (RM) \\
\hline X5 & Railway passenger turnover (RPT) & X12 & $\begin{array}{c}\text { Added value of transportation } \\
\text { industry (AVTI) }\end{array}$ \\
\hline X6 & Highway freight volume (HFV) & X13 & Total population (TP) \\
\hline X7 & Railway freight volume (RFV) & X14 & Transportation investment (TI) \\
\hline
\end{tabular}

\subsection{Competitive Model}

The LV competition model can be used to test competition's influences on resources on the reproductive yield between species (i.e., interspecific competition) and within species (i.e., intraspecific competition), whereby the change in species is formed by using a differential equation. The LV model is an extension of the single-species logistical model to multi-species, where the single-species 
logistical model stands for the species increment that is restricted through intraspecific competition [21]. The logistic model can be expressed by the following equation:

$$
\frac{\mathrm{dX}}{\mathrm{dt}}=(\mathrm{a}-\mathrm{bX}) \mathrm{X}
$$

where $\mathrm{X}$ is the population size at time $\mathrm{t}$, $\mathrm{a}$ is the intrinsic growth rate, $\mathrm{b}$ is the limitation parameter of the niche capacity related to the niche size, and $d X / d t$ is the change of factor $X$ at time $t$. The equation is well-adapted to form a non-linear increment pattern, called the S-curve. Broadening the logistical equation, the LV model for three dependent and varying factors can be symbolized through the following three nonlinear differential equations [22,23],

$$
\frac{d X}{d t}=\left(a_{i}-b_{i j} X_{i}\right) X_{i}-\sum_{j=1, j \neq i}^{3} b_{i j} X_{i} X_{j}, i=1,2,3
$$

where $a_{i}$ and $b_{i j}(i, j=1,2,3)$ are constants. For instance, in LV-COMSUD, GDP, HPV, and RPV are represented by the three factors $X_{1}, X_{2}$, and $X_{3}$ at time $t$, respectively. The alteration of factor $X_{i}$ is modeled according to an equation that contains the logistical increment session (the first session) plus two interaction sessions to explain interspecific competitions between $X_{i}$ and the other two factors. As in Equation (2), the significations of $b_{i j}$ and $a_{i}$ are the same. Parameter $b_{i j}(i \neq j)$ is the competition rate between factors $j$ and $i$. The competition rate assesses the loss in factor $i$ because of factor $j$. The signs of $b_{j i}$ and $b_{i j}$ decide the kinds of competitive positions.

Based on the signs of $b_{i j}$ and $b_{j i}$, six possible types of interaction between the two factors exist, namely:

(1) Pure competition, when $b_{i j}>0$ and $b_{j i}>0$ and both factors inhibit the other's growth;

(2) Mutualism, when $b_{\mathrm{ij}}<0$ and $\mathrm{b}_{\mathrm{ji}}<0$ and both factors enhance the other's growth;

(3) Neutralism, when $b_{i j}=0$ and $b_{j i}=0$ and the two factors have no interaction;

(4) Predator-prey, when $b_{i j}>0$ and $b_{j i}<0$ and factor $i$ enhances factor $j$ 's growth, but factor $j$ inhibits the growth of factor $\mathrm{i}$;

(5) Amensalism, when $b_{i j}>0$ and $b_{j i}=0$ and factor i suffers from the existence of the factor $j$, but factor $j$ is unaffected by factor $i$; and

(6) Commensalism, when $b_{i j}<0$ and $b_{j i}=0$ and factor $i$ obtains benefits from factor $j$ without either harming or benefiting factor $j$.

Considering the deviation of a discrete-time analogue of the Lotka-Volterra model, a discrete version corresponding to Equation (3) proposed by Lewis [20] can be expressed in the most compact form:

$$
X_{i}(t+1)=\frac{\alpha_{i} X_{i}(t)}{1+\sum_{j=1}^{3} \beta_{i j} X_{j}(t)}, i=1,2,3
$$

where

$$
\alpha_{i}=e^{a_{i}} \beta_{i j}=\left(\frac{e^{a_{i}}-1}{a_{i}}\right) b_{i j}, i, j=1,2,3
$$

In Equation (5), the sign for $\beta_{i j}$ must be the same as the sign for $b_{i j}$ since $\left(e^{a_{i}}-1\right) / a_{i}$ is always positive for $a_{i}>0$, and the sign for $a_{i}$ is positive if $\alpha_{i}>1$.

\subsection{ARIMA Models}

The ARIMA procedure analyses and forecasts equally spaced univariate time series data. An ARIMA model's response time series as a linear combination of its own past values and past errors, and its forecasting technique captures a historical data pattern. The ARIMA $(\mathrm{p}, \mathrm{d}, \mathrm{q})$ is expressed as follows [19]:

$$
(1-B){ }^{\mathrm{d}} X_{\mathrm{t}}=\mathrm{u}+\frac{\theta_{\mathrm{q}}(\mathrm{B})}{\varnothing_{\mathrm{p}}(\mathrm{B})} \mathrm{a}_{\mathrm{t}}
$$


where

$$
\begin{gathered}
\varnothing_{p}(B)=1-\varnothing_{1}(B)-\varnothing_{2} B^{2}-\ldots-\varnothing_{p} B^{p} \\
\theta_{q}(B)=1-\theta_{1} B
\end{gathered}
$$

In this equation, $X_{t}$ is the response time series at time $t ; \mathrm{u}$ is the mean term; $\mathrm{B}$ is the backward shift operator; $d$ is the order of regular differences; and $a_{t}, a_{t-1} \ldots$ are independent random shocks. The series $a_{t}$ is assumed to be a white noise process, and $\varnothing_{p}(B)$ and $\theta_{q}(B)$ are polynomials in $B$ of order $p$ and $q$, respectively. The roots of $\varnothing_{p}(B)=0$ and $\theta_{q}(B)=0$ should lie outside the unit circle.

Both LV and ARIMA models just need the independent variables' prevailing values to forecast succeeding values of the dependent variable applying an iterative approach. Additionally, the forecasting approaches are distinct between the LV models and ARIMA. A value is predicted by the ARIMA model in a reaction time series as a linear combination of its own innovations and past values, and its predicting approach is to capture historical information patterns. By contrast, a species value is predicted by the LV model using a nonlinear differential equation to embrace the influences of its interspecific competition and intraspecific competition, and its predicting approach is to capture competitions' impacts among species. The MAPE values originating from the LV and ARIMA models are shown in Table 3, which will be explicated in the following segment.

\section{Results}

\subsection{Descriptive Statistics}

Figure 1 shows the time series for the 14 variables used in the study. From 2014 onwards, HPV, HPT, HFV, HFT and RFV declined slightly, while the remaining indicators showed a clear upward tendency. Table 2 shows the CAGRs (compound annual growth rates) for each variable. We calculated CAGRs for three different time periods (2010-2015, 2005-2015, and 2000-2015), to represent the short-, mediumand long-term growth trends. Comparing the medium- and long-term growth rates with the short-term growth rates, TI and AVTI have the highest short-term growth rates, whereas HPV, HPT, and RFV have the highest short-term decline rates, indicating that nearly five years into the development of the transport industry in Xinjiang, peoples' travel modes began to diversify, and the main mode of highway travel was weakened. Meanwhile, RFV declined slightly because of the influences of highway freight and air freight. The smaller positive CAGR from 2010 to 2015 for GDP remained at more than 10\% growth, which indicates that Xinjiang's economy has been rapidly developing since 2009. Compared with the rapid growth of RPV and RPT, HPV in the short-term and HPT in the short and medium-term are declining. This is not only associated with the rapid development of railway networks in Xinjiang, but also strong proof that Xinjiang's social-economic development is fast-forwarding because of the diversification of travel modes. The decline of RFV in the short-term is due to the expansion of airports in Xinjiang in recent years, which have greatly enhanced the civil aviation cargo capacity, thus having some impact on RFV.

Table 2. Summary of growth rates (\%) of parameters.

\begin{tabular}{lcccccccccccccc}
\hline & GDP & HPV & RPV & HPT & RPT & HFV & RFV & HFT & RFT & HM & RM & AVTI & TI & TP \\
\hline 5-year & 11.4 & -6.1 & 12.6 & -9.8 & 8.2 & 5.0 & -1.9 & 6.7 & 5.4 & 3.1 & 7.0 & 19.2 & 19.6 & 1.6 \\
10-year & 13.6 & 0.2 & 9.3 & -1.2 & 7.3 & 6.9 & 1.5 & 10.1 & 6.1 & 7.1 & 7.7 & 13.6 & 17.0 & 1.6 \\
15-year & 13.7 & 2.6 & 6.0 & 2.9 & 6.6 & 6.0 & 2.7 & 9.5 & 7.6 & 5.4 & 4.9 & 8.9 & 19.2 & 1.6 \\
\hline
\end{tabular}

Notes: 5-year: 2010-2015; 10-year: 2005-2015; 15-year: 2000-2015. 


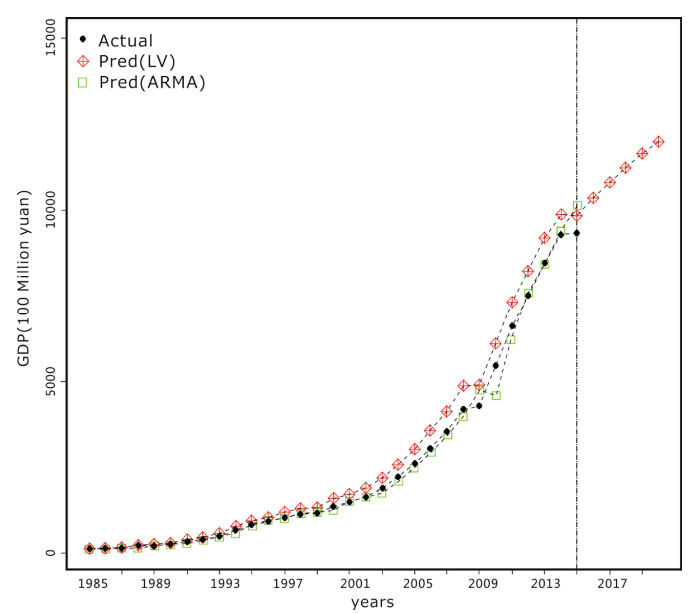

(a)

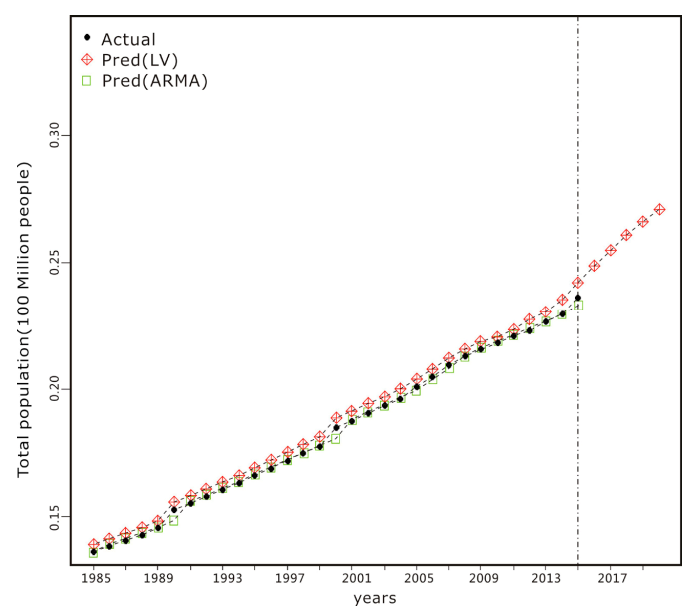

(c)

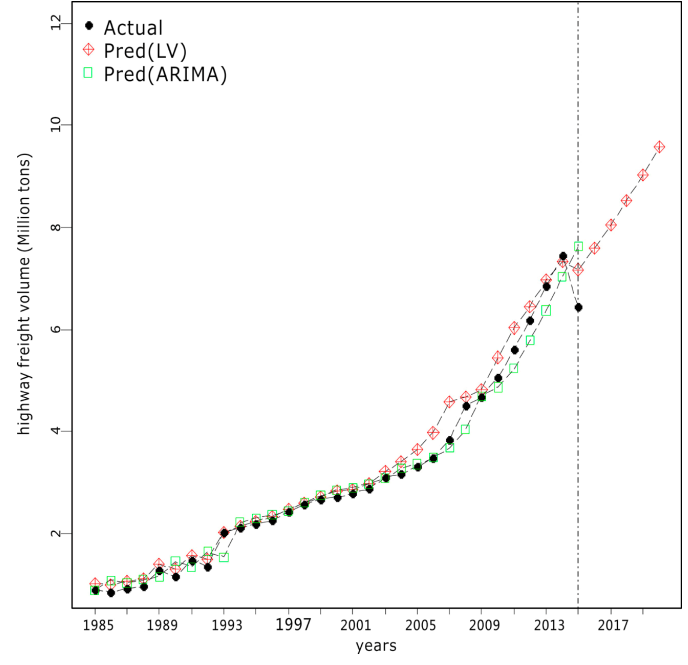

(e)

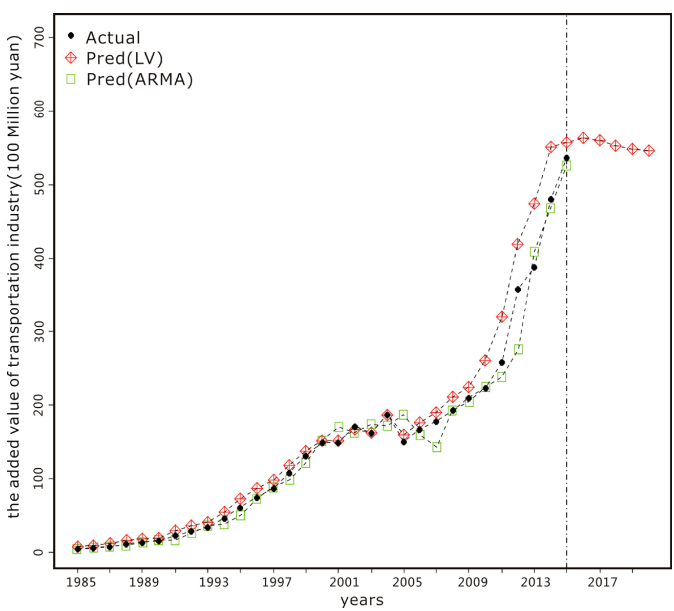

(b)

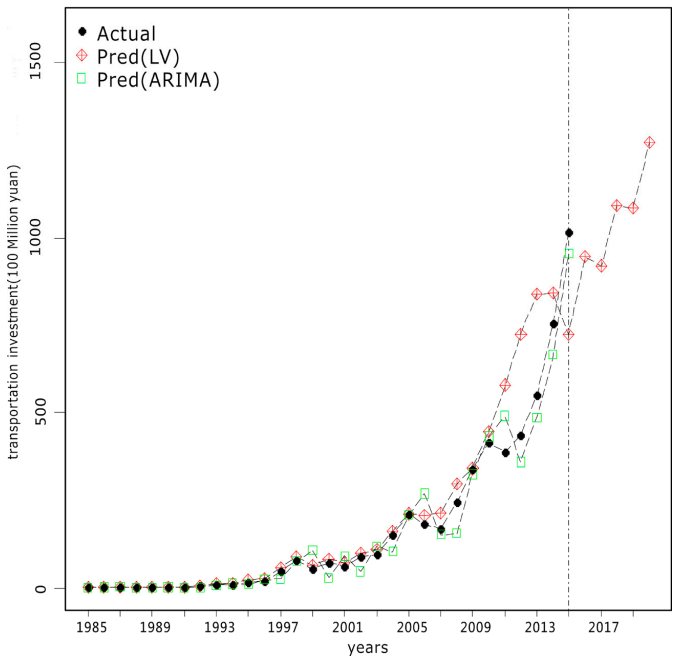

(d)

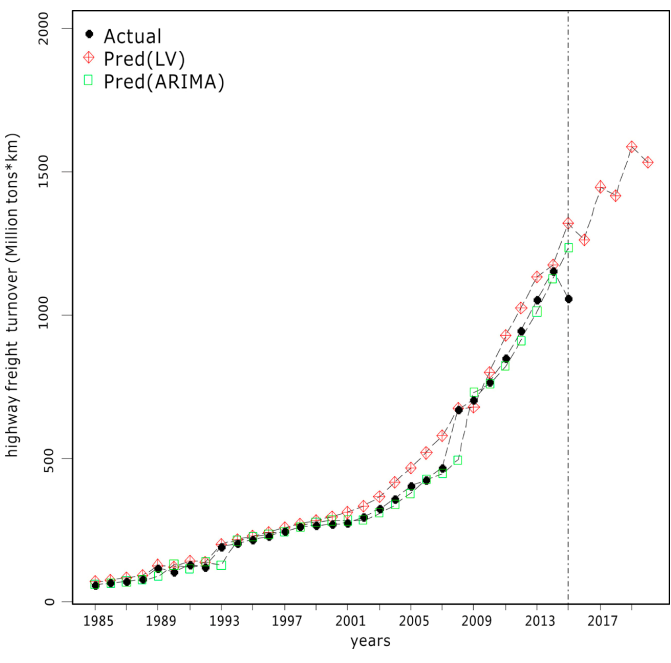

(f)

Figure 1. Cont. 


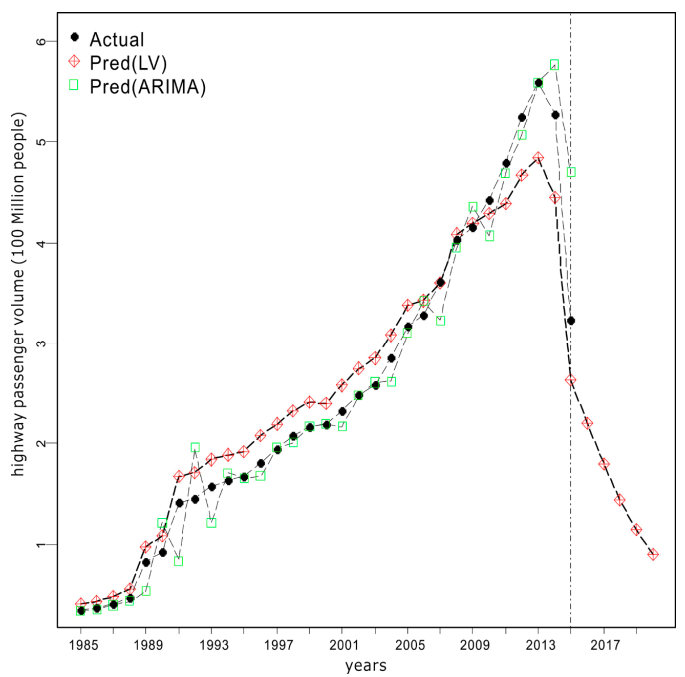

(g)

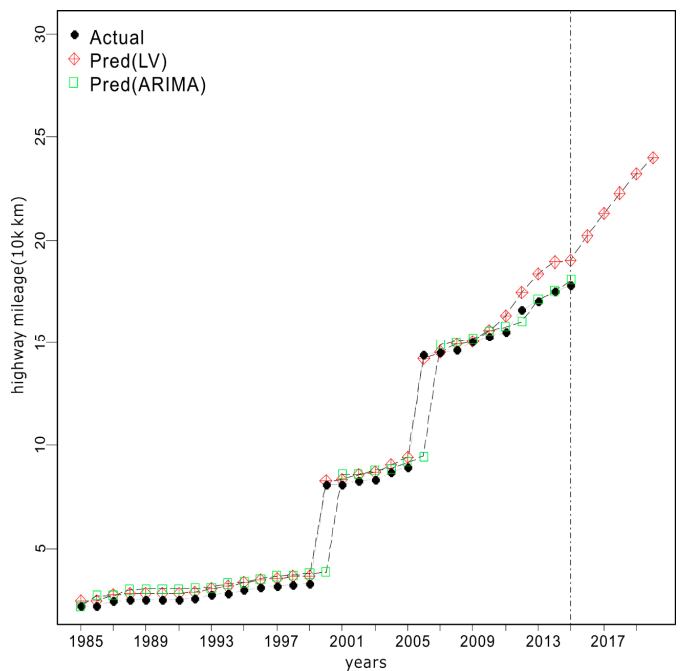

(i)

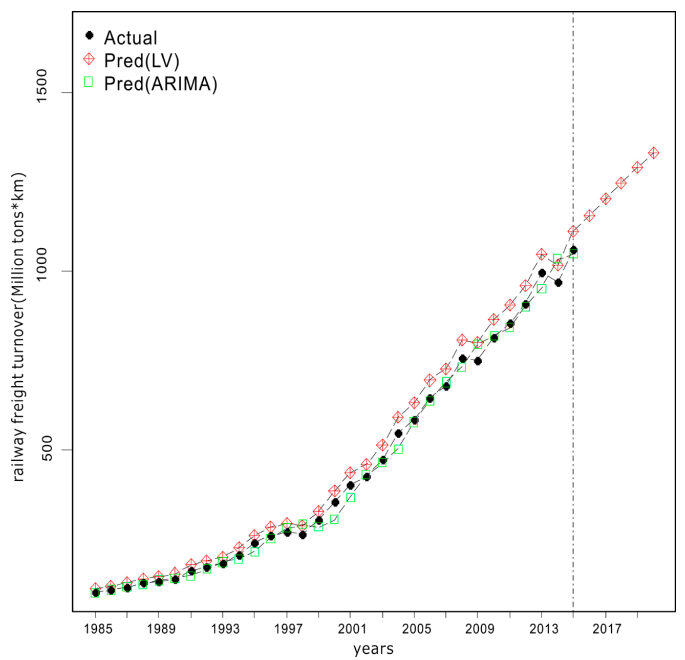

(k)

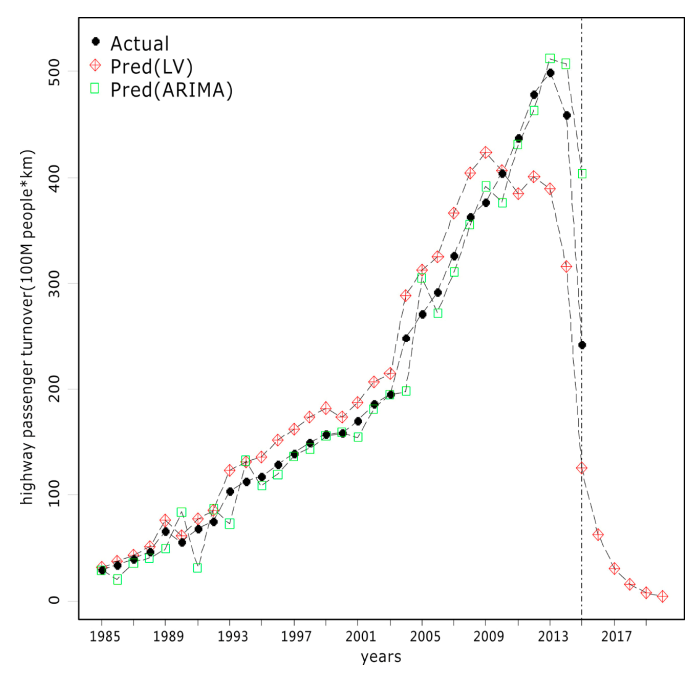

(h)

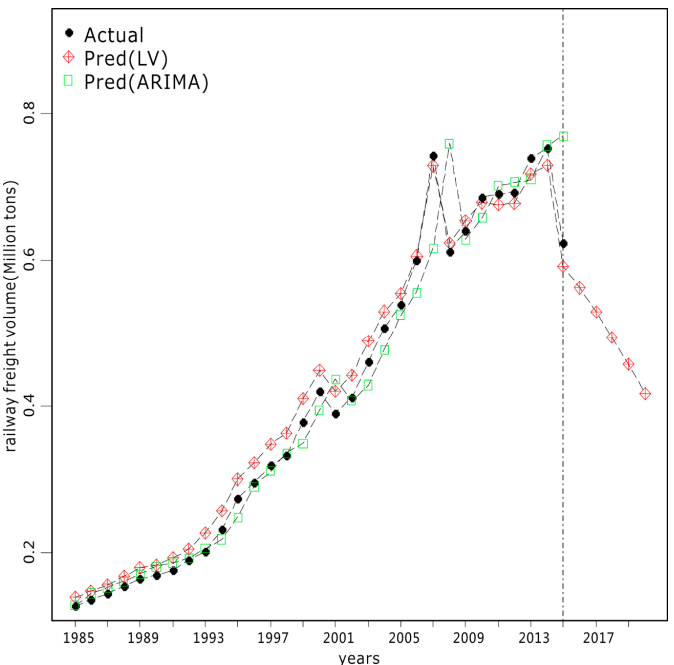

(j)

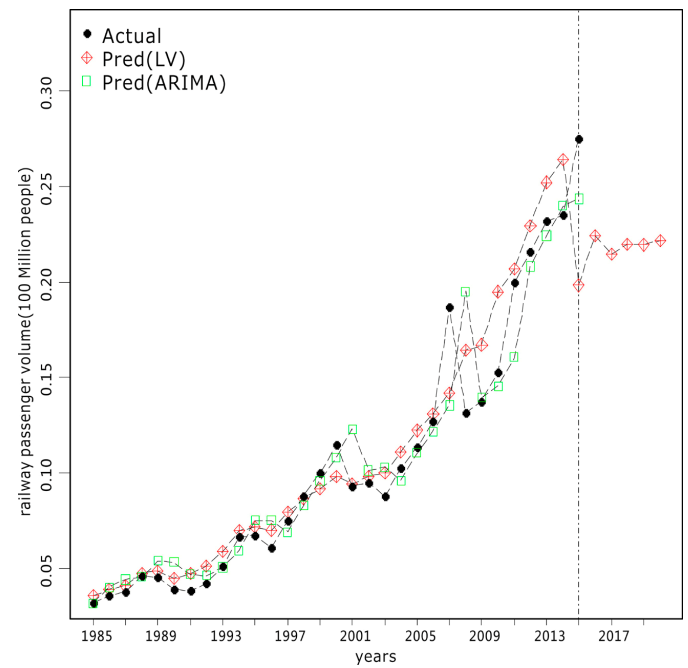

(1)

Figure 1. Cont. 


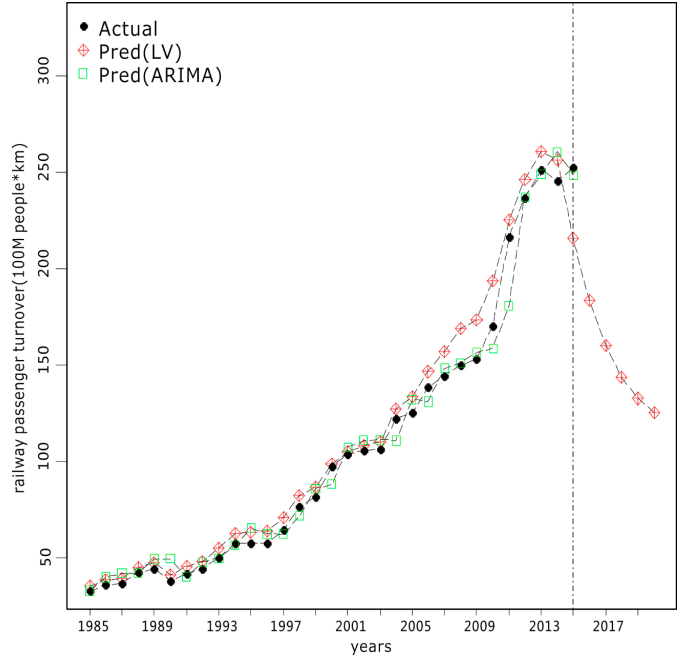

$(\mathbf{m})$

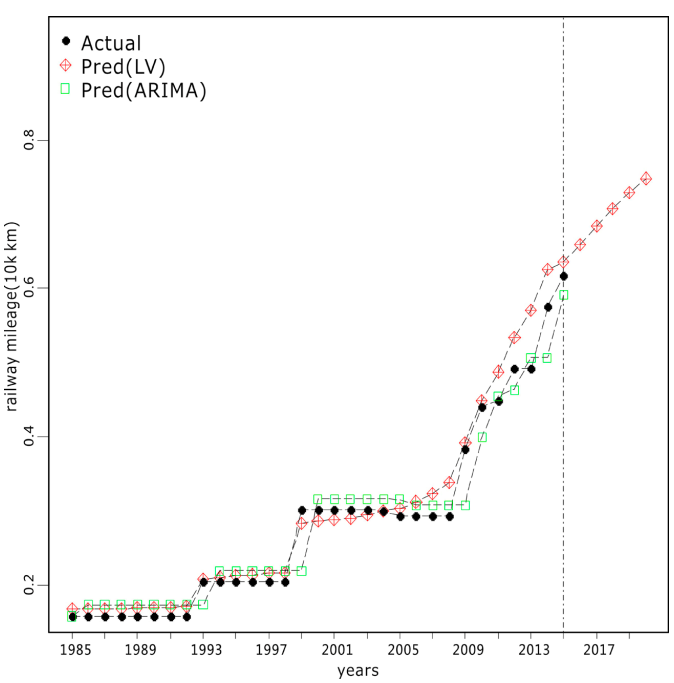

$(\mathbf{n})$

Figure 1. Actual data and model output (Actual: Actual data of each variable from 1985 to 2015; Pred (LV): Lotka-Volterra model prediction; Pred (ARIMA): Autoregressive integrated moving average results). (a) the variation tendency of GDP; (b) the variation tendency of AVTI; (c) the variation tendency of TP; (d) the variation tendency of TI; (e) the variation tendency of HFV; (f) the variation tendency of HFT; (g) the variation tendency of HPV; (h) the variation tendency of HPT; (i) the variation tendency of $\mathrm{HM}$; (j) the variation tendency of RFV; (k) the variation tendency of RFT; (1) the variation tendency of RPV; (m) the variation tendency of RPT; (n) the variation tendency of RM). Notes: Meanings of abbreviations in Figure 1 are all refer to Table 1.

\subsection{Analysis of the Competitive Relationships}

In this section, we adopt the discrete-time LV-COMSUD to analyze the competitive relationship between land transportation and GDP. Furthermore, the competitive relationships among different types of land transportation (including highway transportation and railway transportation) have also been analyzed. The MODEL procedure in the R language application is used to analyze and predict concurrent nonlinear equation systems. We use the nonlinear ordinary least-squares estimation and the Gauss-Newton iterative method which minimizes the sum of squares of "linearized" innovations to fit and solve simultaneous equations. Based on the relative offset orthogonality convergence standard, the iterations are executed to converge with a termination value of 0.001 .

\subsubsection{The Relationship between GDP and Land Transportation}

To analyze the competitive relationships among different types of land transportation (including highway transportation and railway transportation) and GDP, the parameters in Equation (3) are estimated. The estimation results and R-squares are summarized in panels A to E of Table 3.

Using Equation (4), the estimated parameters of $\alpha_{\mathrm{i}}$ and $\beta_{\mathrm{ij}}$ in Equation (3) are transformed into estimated parameters of $a_{i}$ and $b_{i j}$ in Equation (1). The sign of $\beta_{i j}$ is the same as the sign of $b_{i j}$, since $\left(e^{a_{i}}-1\right) / a_{i}$ is always positive for $a_{i}>0$, and the sign of $a_{i}$ is positive if $\alpha_{i}>1$. In each of the Lotka-Volterra models, R-squared is greater than 0.90 , except for the added value of transportation industry, where R-squared is 0.80 . The MAPE value is 0.23 and 0.24 for the added value of transportation industry and transportation investment, and less than 0.20 for all other analyses. Based on the criteria of Lewis [20], all equations show highly accurate forecasts. The results are summarized in Table 3. 
Table 3. Estimation results for land transportation and GDP, 1985 2015.

\begin{tabular}{|c|c|c|c|c|c|c|c|c|}
\hline \multicolumn{9}{|c|}{ Panel A: GDP-HPV-RPV } \\
\hline \multicolumn{3}{|c|}{ GDP } & \multicolumn{3}{|c|}{ HPV } & \multicolumn{3}{|c|}{ RPV } \\
\hline Parameter & Estimates & t-Stat & Parameter & Estimates & t-Stat & Parameter & Estimates & t-Stat \\
\hline$\alpha_{1}$ & $1.23^{* * *}$ & 11.88 & $\alpha_{2}$ & $1.21^{* *}$ & 2.59 & $\alpha_{3}$ & $1.41^{* *}$ & 2.62 \\
\hline$\beta_{11}$ & $-3.48 \times 10^{-6 * * *}$ & 14.82 & $\beta_{21}$ & $3.61 \times 10^{-5 * * *}$ & -3.08 & $\beta_{31}$ & $-1.50 \times 10^{-4 * * *}$ & 2.89 \\
\hline$\beta_{12}$ & $-0.02 * *$ & 2.54 & $\beta_{22}$ & $-0.01^{* * *}$ & 8.37 & $\beta_{32}$ & $-0.15^{*}$ & 1.88 \\
\hline$\beta_{13}$ & 1.15 & -0.40 & $\beta_{23}$ & 0.66 & 0.20 & $\beta_{33}$ & 10.28 & 1.11 \\
\hline $\mathbf{R}^{2}$ & 0.98 & & & 0.96 & & & 0.92 & \\
\hline MAPE & 0.16 & & & 0.12 & & & 0.11 & \\
\hline \multicolumn{9}{|c|}{ Panel B: GDP-HPT-RPT } \\
\hline \multicolumn{3}{|c|}{ GDP } & \multicolumn{3}{|c|}{ HPT } & \multicolumn{3}{|c|}{ RPT } \\
\hline Parameter & Estimates & t-Stat & Parameter & Estimates & $\mathrm{t}$-Stat & Parameter & Estimates & t-Stat \\
\hline$\alpha_{1}$ & $1.26^{* * *}$ & 11.88 & $\alpha_{2}$ & $1.09 * *$ & 2.29 & $\alpha_{3}$ & $1.16^{* *}$ & 4.90 \\
\hline$\beta_{11}$ & $-1.13 \times 10^{-5 * * *}$ & 12.35 & $\beta_{21}$ & $1.25 \times 10^{-4 * * *}$ & -4.55 & $\beta_{31}$ & $-3.23 \times 10^{-5}$ & 0.38 \\
\hline$\beta_{12}$ & $-7.19 \times 10^{-4 * * *}$ & 3.57 & $\beta_{22}$ & $-2.28 \times 10^{-3 * * *}$ & 8.41 & $\beta_{32}$ & $-1.02 \times 10^{-3 * *}$ & 2.61 \\
\hline$\beta_{13}$ & $2.49 \times 10^{-3}$ & -0.99 & $\beta_{23}$ & $1.91 \times 10^{-3}$ & 0.34 & $\beta_{33}$ & $3.60 \times 10^{-3 * * *}$ & 3.79 \\
\hline $\mathbf{R}^{2}$ & 0.98 & & & 0.91 & & & 0.98 & \\
\hline MAPE & 0.16 & & & 0.14 & & & 0.07 & \\
\hline \multicolumn{9}{|c|}{ Panel C: GDP-HFV-RFV } \\
\hline \multicolumn{3}{|c|}{ GDP } & \multicolumn{3}{|c|}{ HFV } & \multicolumn{3}{|c|}{ RFV } \\
\hline Parameter & Estimates & $\mathrm{t}$-Stat & Parameter & Estimates & t-Stat & Parameter & Estimates & t-Stat \\
\hline$\alpha_{1}$ & $1.29^{* * *}$ & 11.88 & $\alpha_{2}$ & $1.28^{* * *}$ & 3.45 & $\alpha_{3}$ & $1.07^{* * *}$ & 3.43 \\
\hline$\beta_{11}$ & $-3.31 \times 10^{-5 * * *}$ & 12.26 & $\beta_{21}$ & $-9.76 \times 10^{-5}$ & 1.25 & $\beta_{31}$ & $3.48 \times 10^{-5}$ & -1.44 \\
\hline$\beta_{12}$ & 0.08 & -1.17 & $\beta_{22}$ & $0.22^{* * *}$ & 2.89 & $\beta_{32}$ & -0.05 & 0.99 \\
\hline$\beta_{13}$ & $-0.16^{* *}$ & 2.76 & $\beta_{23}$ & $-0.58^{* *}$ & 2.71 & $\beta_{33}$ & $0.23^{* * *}$ & 7.94 \\
\hline $\mathbf{R}^{2}$ & 0.98 & & & 0.98 & & & 0.99 & \\
\hline MAPE & 0.16 & & & 0.07 & & & 0.06 & \\
\hline
\end{tabular}


Table 3. Cont.

\begin{tabular}{|c|c|c|c|c|c|c|c|c|}
\hline \multicolumn{9}{|c|}{ Panel D: GDP-HFT-RFT } \\
\hline \multicolumn{3}{|c|}{ GDP } & \multicolumn{3}{|c|}{ HFT } & \multicolumn{3}{|c|}{ RFT } \\
\hline Parameter & Estimates & t-Stat & Parameter & Estimates & t-Stat & Parameter & Estimates & t-Stat \\
\hline$\alpha_{1}$ & $1.21^{* * *}$ & 11.88 & $\alpha_{2}$ & $1.23^{* * *}$ & 4.42 & $\alpha_{3}$ & $1.10^{* * *}$ & 8.87 \\
\hline$\beta_{11}$ & $-1.16 \times 10^{-5 * * *}$ & 6.64 & $\beta_{21}$ & $-1.58 \times 10^{-4}$ & 1.08 & $\beta_{31}$ & $6.05 e-07$ & 0.04 \\
\hline$\beta_{12}$ & $2.43 \times 10^{-4}$ & 0.13 & $\beta_{22}$ & $1.82 \times 10^{-3 * *}$ & 2.22 & $\beta_{32}$ & $1.96 \times 10^{-5}$ & -0.33 \\
\hline$\beta_{13}$ & $-5.17 \times 10^{-5 * *}$ & 2.66 & $\beta_{23}$ & $-4.39 \times 10^{-4 * * *}$ & 3.35 & $\beta_{33}$ & $2.32 \times 10^{-5 * * *}$ & 17.00 \\
\hline $\mathbf{R}^{2}$ & 0.98 & & & 0.98 & & & 0.99 & \\
\hline MAPE & 0.16 & & & 0.10 & & & 0.08 & \\
\hline \multicolumn{9}{|c|}{ Panel E: GDP-HM-RM } \\
\hline \multicolumn{3}{|c|}{ GDP } & \multicolumn{3}{|c|}{ HM } & \multicolumn{3}{|c|}{$\mathbf{R M}$} \\
\hline Parameter & Estimates & t-Stat & Parameter & Estimates & t-Stat & Parameter & Estimates & t-Stat \\
\hline$\alpha_{1}$ & $1.23 * * *$ & 11.88 & $\alpha_{2}$ & $1.19^{* *}$ & 2.16 & $\alpha_{3}$ & $1.35^{* *}$ & 2.50 \\
\hline$\beta_{11}$ & $7.66 \times 10^{-6 * * *}$ & 14.93 & $\beta_{21}$ & $-3.44 \times 10^{-5}$ & -0.91 & $\beta_{31}$ & $-8.38 \times 10^{-5 * *}$ & 2.63 \\
\hline$\beta_{12}$ & $-3.35 \times 10^{-3 * *}$ & 2.49 & $\beta_{22}$ & $1.66 \times 10^{-2 * * *}$ & 8.67 & $\beta_{32}$ & $-1.98 \times 10^{-5}$ & -0.03 \\
\hline$\beta_{13}$ & 0.25 & 0.71 & $\beta_{23}$ & 0.22 & 1.68 & $\beta_{33}$ & $1.77^{* * *}$ & 4.92 \\
\hline $\mathbf{R}^{2}$ & 0.98 & & & 0.99 & & & 0.95 & \\
\hline MAPE & 0.16 & & & 0.07 & & & 0.06 & \\
\hline \multicolumn{9}{|c|}{ Panel F: GDP-AVTI-TI } \\
\hline \multicolumn{3}{|c|}{ GDP } & \multicolumn{3}{|c|}{ AVTI } & \multicolumn{3}{|c|}{ TI } \\
\hline Parameter & Estimates & $\mathrm{t}$-Stat & Parameter & Estimates & $\mathrm{t}-$ Stat & Parameter & Estimates & t-Stat \\
\hline$\alpha_{1}$ & $1.22 * * *$ & 11.88 & $\alpha_{2}$ & $1.31^{* * *}$ & 6.56 & $\alpha_{3}$ & $1.24^{* * *}$ & 3.97 \\
\hline$\beta_{11}$ & $-1.37 \times 10^{-5 * * *}$ & 11.63 & $\beta_{21}$ & $-1.10 \times 10^{-4 * * *}$ & 3.26 & $\beta_{31}$ & $-1.14 \times 10^{-4}$ & 0.10 \\
\hline$\beta_{12}$ & $7.83 \times 10^{-4}$ & -1.22 & $\beta_{22}$ & $2.93 \times 10^{-3 * * *}$ & 8.58 & $\beta_{32}$ & $6.07 \times 10^{-4}$ & 1.44 \\
\hline$\beta_{13}$ & $-1.28 \times 10^{-4}$ & -0.95 & $\beta_{23}$ & $-8.96 \times 10^{-5}$ & -1.21 & $\beta_{33}$ & $1.34 \times 10^{-3 * * *}$ & 5.18 \\
\hline $\mathbf{R}^{2}$ & 0.98 & & & 0.95 & & & 0.93 & \\
\hline MAPE & 0.16 & & & 0.18 & & & $(0.23)$ & \\
\hline
\end{tabular}


Table 3. Cont.

\begin{tabular}{|c|c|c|c|c|c|c|c|c|}
\hline \multicolumn{9}{|c|}{ Panel G: GDP-AVTI-TP } \\
\hline \multicolumn{3}{|c|}{ GDP } & \multicolumn{3}{|c|}{ AVTI } & \multicolumn{3}{|c|}{ TP } \\
\hline Parameter & Estimates & t-Stat & Parameter & Estimates & t-Stat & Parameter & Estimates & $\mathrm{t}$-Stat \\
\hline$\alpha_{1}$ & $1.38^{* * *}$ & 11.88 & $\alpha_{2}$ & $28.70 * * *$ & 6.56 & $\alpha_{3}$ & $1.05^{* * *}$ & 12.21 \\
\hline$\beta_{11}$ & $-2.58 \times 10^{-5 * * *}$ & 22.84 & $\beta_{21}$ & $-2.65 \times 10^{-3 * * *}$ & 3.78 & $\beta_{31}$ & $2.12 \times 10^{-6}$ & -1.43 \\
\hline$\beta_{12}$ & $6.86 \times 10^{-4 * * *}$ & -3.63 & $\beta_{22}$ & $3.47 \times 10^{-2 * * *}$ & 7.37 & $\beta_{32}$ & $-8.92 \times 10^{-5 * *}$ & 2.08 \\
\hline$\beta_{13}$ & $0.87^{* * *}$ & 4.16 & $\beta_{23}$ & 138.57 & -0.49 & $\beta_{33}$ & $0.23^{* * *}$ & 45.08 \\
\hline $\mathbf{R}^{2}$ & 0.98 & & & 0.94 & & & 0.99 & \\
\hline MAPE & 0.16 & & & 0.18 & & & 0.02 & \\
\hline \multicolumn{9}{|c|}{ Panel H: GDP-TI-TP } \\
\hline \multicolumn{3}{|c|}{ GDP } & \multicolumn{3}{|c|}{ TI } & \multicolumn{3}{|c|}{ TP } \\
\hline Parameter & Estimates & t-Stat & Parameter & Estimates & t-Stat & Parameter & Estimates & t-Stat \\
\hline$\alpha_{1}$ & $1.61^{* * *}$ & 11.88 & $\alpha_{2}$ & $8.44 \times 10^{35 * * *}$ & 3.97 & $\alpha_{3}$ & $1.04^{* * *}$ & 12.21 \\
\hline$\beta_{11}$ & $-1.40 \times 10^{-5 * * *}$ & 10.53 & $\beta_{21}$ & $-1.61 \times 10^{32}$ & 1.53 & $\beta_{31}$ & $2.15 \times 10^{-6}$ & -0.97 \\
\hline$\beta_{12}$ & $9.37 \times 10^{-5}$ & -0.85 & $\beta_{22}$ & $1.57 \times 10^{33 * * *}$ & 5.17 & $\beta_{32}$ & $-3.66 \times 10^{-5}$ & 1.16 \\
\hline$\beta_{13}$ & $2.25 *$ & 2.04 & $\beta_{23}$ & $4.61 \times 10^{36}$ & -1.65 & $\beta_{33}$ & $0.10^{* * *}$ & 50.68 \\
\hline $\mathbf{R}^{2}$ & 0.98 & & & $(0.80)$ & & & 0.99 & \\
\hline MAPE & 0.16 & & & $(0.24)$ & & & 0.02 & \\
\hline
\end{tabular}

Notes: ***,**, and * indicate $1 \%, 5 \%$, and $10 \%$ levels of statistical significance, respectively. Figures in parentheses are MAPEs of ARIMA models. 
Panel A of Table 3 shows the results for the GDP-HPV-RPV competitive model. Estimated $\beta_{12}$, $\beta_{21}, \beta_{31}$, and $\beta_{32}$ are statistically significant; other effects are statistically insignificant. The relationship between $\beta_{12}$ and $\beta_{21}$ is predator-prey; that is, HPV enhances the growth of GDP, but GDP has a significant weakening effect on HPV. The statistically insignificant $\beta_{13}$ and $\beta_{31}$ indicate a commensalism relationship, where RPV benefits from GDP without either harming or benefiting GDP. The relationship between $\beta_{23}$ and $\beta_{32}$ is also commensalism. This indicates that RPV benefits from HPV without either harming or benefiting the latter. We can conclude that the interaction between HPV and GDP is significant. This can be explained by the fact that, with the development of the social economy, people have more flexibility in choosing their way to travel (if time is abundant and the place is far away from their residence, they will choose the train, which contributes to the growth of RPV), resulting in a decrease in HPV. Meanwhile, increasing HPV will greatly promote population circulation, and thus indirectly promote consumption, which can increase GDP. Compared with the highway, the railway has its own advantages: high numbers of passengers, a high safety factor, and long transport distance. Xinjiang is geographically distant, which complements the short board of highway passenger transport, so the RPV benefits from HPV are therefore decided by the natural and geographical conditions in Xinjiang.

Panel B of Table 3 shows the results for the GDP-HPT-RPT competitive model. Estimated $\beta_{12}$, $\beta_{21}$, and $\beta_{32}$ are statistically significant; other effects are statistically insignificant. The relationship between $\beta_{12}$ and $\beta_{21}$ is the same as GDP and HPV. $\beta_{13}$ and $\beta_{31}$ indicate a neutralism relationship, where the interaction between GDP and RPT is negligible. The relationship between $\beta_{23}$ and $\beta_{32}$ is commensalism, which means RPT benefits from HPT without either harming or benefiting the latter. In addition to the benefit from HPT, the effect of RPT on GDP is negligible, which proves that, in the short- and medium-term, highway transportation is the main mode of travel for Xinjiang.

Panel C of Table 3 shows the results for the GDP-HFV-RFV competitive model. Estimated $\beta_{13}$ and $\beta_{23}$ are statistically significant; other effects are statistically insignificant. $\beta_{12}$ and $\beta_{21}$ have a neutralism relationship, where the interaction between GDP and HFV is negligible. $\beta_{13}$ and $\beta_{31}$ indicate a commensalism relationship, where GDP benefits from RFV without either harming or benefiting the latter. The relationship between $\beta_{23}$ and $\beta_{32}$ is also commensalism, where HFV benefits from RFV without either harming or benefiting the latter. Because of the limitation of truck load and the influence of weather, there are shortcomings in HFV, such as high cost and low loading. Moreover, considering the long geographical distance between regions, it is not the mainstream mode of transportation for goods in Xinjiang. Therefore, the impact of HFV on GDP is negligible. Meanwhile, RFV, with the advantages of long-distance transport, large cargo volumes, and lack of weather issues, as well as its low price and high safety factor, has become the first choice for bulk cargo transport in Xinjiang. The circulation of large quantities of goods has promoted import and export trade, which has contributed to the development of the local economy. HFV benefits from RFV because of its flexible mobility, which allows travel to places trains and planes cannot reach, complementing the short board of fixed line railway freight transport. It is apparent that the relationship between HFV and RFV and their relationship with GDP are closely related to the local geographical conditions in Xinjiang.

Panel D of Table 3 shows the results for the GDP-HFT-RFT competitive model. Estimated $\beta_{13}$ and $\beta_{23}$ are statistically significant; other effects are statistically insignificant. $\beta_{12}$ and $\beta_{21}$ have a neutralism relationship, where GDP and HFT barely influence each other. $\beta_{13}$ and $\beta_{31}$ indicate a commensalism relationship, where GDP benefits from RFT without either harming or benefiting the latter. The relationship between $\beta_{23}$ and $\beta_{32}$ is the same as HFV and RFV. The relationships of the indicators in Panel D are the same as those in Panel $C$, and the reasons are also consistent.

Panel E of Table 3 shows the results for the GDP-HM-RM competitive model. Estimated $\beta_{12}$ and $\beta_{31}$ are statistically significant; other effects are statistically insignificant. $\beta_{12}$ and $\beta_{21}$ have a commensalism relationship, where GDP benefits from HM without either harming or benefiting the latter. $\beta_{13}$ and $\beta_{31}$ also indicate a commensalism relationship, which shows that RM benefits from GDP without either harming or benefiting GDP. $\beta_{23}$ and $\beta_{32}$ indicate a neutralism relationship, where HM 
and RM barely influence each other. The highway can achieve "point-to-point" transportation, is flexible and convenient, and can reach a wide range, so the increase in HM not only promotes population circulation in Xinjiang territory and between the other provinces, but also acts as a supplement to the short board of rail transport of goods. In this way, it plays an important role in promoting the rapid growth of GDP, while the rapid growth of GDP, in turn, can provide reliable financial support for the expansion of Xinjiang's railway network. However, railways and highways are two separate modes of transportation, and their development models are completely different; therefore, we conclude that though the commensalism between them and GDP is significant, it does not lead to a linear relationship.

4.2.2. The Competitive Relationship among the Economic Indicators of Transportation and Their Relationship with GDP

To analyze the competitive relationships among the economic indicators of transportation and their relationship with GDP, the parameters of Equation (3) are estimated again. The estimation results and R-squared are given in panels $\mathrm{F}$ to $\mathrm{H}$ of Table 3.

Panel F of Table 3 shows the results for the GDP-AVTI-TI competitive model. Estimated $\beta_{21}$ is statistically significant; other effects are statistically insignificant. $\beta_{12}$ and $\beta_{21}$ indicate a commensalism relationship, where AVTI benefits from GDP without either harming or benefiting the latter. $\beta_{13}$ and $\beta_{31}$ indicate a neutralism relationship, and $\beta_{23}$ and $\beta_{32}$ are the same. This indicates that there is barely any interaction between these factors. GDP includes AVTI, which is part of the tertiary industry in GDP. Therefore, GDP will increase accordingly as AVTI increases. The interaction between TI and AVTI is negligible, because the relationship between them is not a simple "input-output" relationship, but is instead very complicated. Studies have shown that several cities in the same region have adopted the same strategy of increasing transportation investment to promote local economic development, but the results differ. Transport investment does not necessarily lead to economic development; only under certain conditions can transportation investment stimulate and promote economic development $[24,25]$.

Panel G of Table 3 presents the results for the GDP-AVTI-TP competitive model. $\beta_{31}$ and $\beta_{23}$ are statistically insignificant; all other effects are statistically significant. The relationship between $\beta_{12}$ and $\beta_{21}$ is predator-prey; that is, GDP enhances the growth of AVTI, but GDP is weakened to a certain degree by the latter. $\beta_{13}$ and $\beta_{31}$ indicate an amensalism relationship, where TP inhibits the growth of GDP, and TP is unaffected by GDP. $\beta_{23}$ and $\beta_{32}$ indicate a commensalism relationship, where TP benefits from AVTI without either harming or benefiting the latter. Xinjiang is a typical oasis economy region, which means its economic development is determined by its natural resources. The consumption of resources caused by an increasing population places great pressure on the limited resources of the oasis, and this will have a negative impact on its economy's sustainable development, thus slowing the growth rate of GDP. The increase in AVTI can enable people to travel more conveniently, which greatly increases the circulation of personnel between counties and cities. The contribution of GDP to AVTI has been explained in the discussion of Panel F. Due to the long investment cycle of transportation infrastructure construction and the lag in its economic benefits, transportation investment will have a negative impact on the development of other industries in the short-term, thus affecting the rapid development of the overall national economy.

Panel H of Table 3 shows the results for the GDP-TI-TP competitive model. Estimated $\beta_{13}$ is statistically significant; other effects are statistically insignificant. $\beta_{12}$ and $\beta_{21}$ indicate a neutralism relationship, and $\beta_{23}$ and $\beta_{32}$ are the same. This shows the interaction between these factors is negligible. TI and TP are of different statistical categories, so there is no linear relationship.

In Figure 2, we summarize all the statistically significant results from the LV-COMSUD models. In summary, the interactions among land transportation and GDP derived from the LV-COMSUD models include: (1) Predator-prey, such as where HPV and HPT enhance the growth of GDP, but GDP has a significant weakening effect on them. (2) Commensalism, where GDP benefits from HM without 
either harming or benefiting the latter. (3) Neutralism, where TI, GDP, AVTI, and TP barely influence each other. (4) Amensalism, as seen when TP inhibits the growth of GDP, and TP is unaffected by GDP.

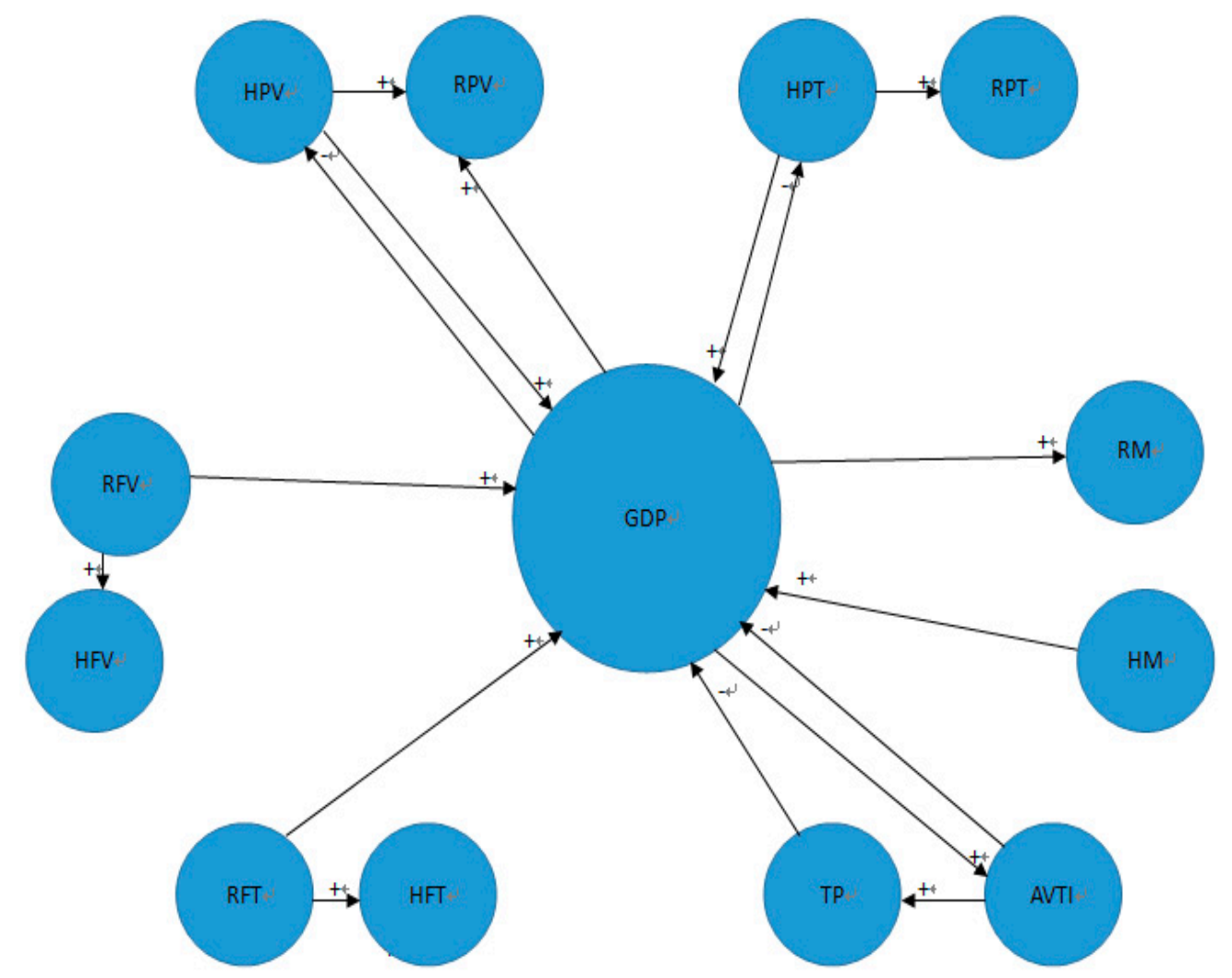

Figure 2. Dynamic competitive relationships among land transportation and GDP.

\subsection{Forecasting Land Transportation, the Economic Indicators of Transportation and GDP}

Due to the data itself, there is a large error in the prediction of the ARIMA model. Therefore, when predicting future data, only the prediction results of the LV model are used. The multivariate LV-COMSUD model is estimated using actual Xinjiang data from 1985 to 2015 to predict the variables of land transportation and GDP. The MAPE statistics, computed as in Equation (1), are used to assess these models' in-sample forecasting ability. The model has good predictive ability, as reflected in the MAPEs of less than 0.2 in Table 4.

For the out-of-sample forecast of land transportation and GDP in Xinjiang from 2016 to 2020, the results using LV-COMSUD models are displayed in Figure 1 and Table 4 . Table 4 also shows the 5-year CAGRs between 2016 and 2020 for variables in the LV-COMSUD models. According to Table 3, we can conclude that HPV and RFV will decline in the next five years (HPV especially decreases by $19.4 \%$ ), while the others will maintain a slow upward trend. This is because the policy of the 'Thirteenth Five-Year Plan' in Xinjiang promotes the coordinated development of various modes of transportation, which will make transportation modes more flexible.

Because the four indicators, GDP, AVTI, TP, and TI, were included in two or more forecasts, the final results are selected based on the MAPE values in each group and the degree of closeness to the actual value. Based on the criteria in Lewis [20], the prediction results shown in Panels G, E, and H are reasonable. RE-LV (2016) and RE-LV (2020) are the relative errors of the predicted values and the actual target values in 2016 and 2020, respectively. 
Table 4. Forecast of parameters, 2016-2020.

\begin{tabular}{ccccccccccc}
\hline & GDP & HPV & RPV & HFV & RFV & HM & RM & AVTI & TI & TP \\
\hline 2016 & $10,336.9$ & 2.21 & 0.22 & 7.59 & 0.56 & 20.18 & 0.66 & 562.97 & 949.1 & 0.25 \\
2017 & $10,807.07$ & 1.79 & 0.21 & 8.04 & 0.53 & 21.28 & 0.68 & 559.81 & 921.9 & 0.26 \\
2018 & $11,240.44$ & 1.44 & 0.22 & 8.52 & 0.49 & 22.28 & 0.71 & 553.25 & 1093.0 & 0.26 \\
2019 & $11,634.49$ & 1.14 & 0.22 & 9.04 & 0.46 & 23.19 & 0.73 & 547.84 & 1086.1 & 0.27 \\
2020 & $11,988.91$ & 0.90 & 0.22 & 9.59 & 0.42 & 24.00 & 0.75 & 546.63 & 1274.4 & 0.27 \\
CAGR-lv (\%) & 5.15 & -19.40 & 2.24 & 5.97 & -6.75 & 4.76 & 3.33 & 0.39 & 4.61 & 2.81 \\
RE-LV (2016) & 0.07 & -0.24 & -0.3 & 0.17 & -0.19 & 0.11 & -0.07 & -0.01 & 0.14 & 0.04 \\
RE-LV(2020) & -0.08 & -0.9 & -0.62 & -0.24 & -0.76 & 0.26 & -0.25 & -0.15 & -0.03 & 0.03 \\
\hline
\end{tabular}

Note: CAGR-LV (\%) is annual growth rate in 5-year for the average forecasting result of LV models. RE-LV (2016) and RE-LV (2020) are the relative errors of the predicted values and the actual target values in 2016 and 2020, respectively.

\section{Conclusions and Discussion}

This study employs the LV-COMSUD model to capture the competitive interactions among GDP and land transportation, as well as the competitive interactions among different types of land transportation (highway and railway). Understanding the different types of interactions among GDP and land transportation (mutualism, commensalism, predator-prey, amensalism, or neutralism) not only facilitates policy development to achieve a balance in the relationship between economy and transportation, but can also provide technical support and a scientific basis for the advancement of transportation development planning.

Our findings have important practical implications. In particular, the findings suggest the following. (1) HM, highway passenger transportation, and railway freight transportation have a large positive impact on promoting the national economy of Xinjiang, which will weaken the development of highway passenger transportation and promote the development of railway passenger transportation, railway mileage, and AVTI. (2) Highway passenger transportation promotes the development of railway passenger transportation, while rail freight transportation has played an important role in promoting highway freight transportation in Xinjiang. (3) The increase of AVTI is conducive to the growth of TP, but both have a certain negative impact on the national economy in the short-term. (4) There is no significant relationship between TI and the national economy. The fourth conclusion is consistent with some of the existing research. The quantitative correlation between transportation construction investment and GDP growth has been analyzed, but the studies were unable to reveal the direct effect of regional leading industry through transportation construction investment in selected cities [26-29]. In addition, transportation infrastructure construction has different impacts on regional economic development, which are caused by changes in the socio-economic environments studied. This shows that technological factors (especially advances in information technology leading to the flow of intangible elements of production, such as increased information and funds) and increasing efficiency became more and more essential to regional economic development, which may lead to an obvious result that additional transportation investment in the original socio-economic environment can stimulate and promote economic development. Meanwhile, with the changes in environment, it is possible that additional transportation investment will become a serious burden to economic development; a high-quality infrastructure is not a necessary condition for emerging areas in recession or economic growth [30].

Xinjiang has unique natural and geographical conditions, as well as a special strategic position, and the reality is that there may still be a giant gap between rich and poor people [31]; the level of economic development in Xinjiang is in a backward position in the country. The primary task of economic development is poverty alleviation and the maintenance of social stability; therefore, many infrastructure investments have focused on this target. On the other hand, transportation infrastructure construction requires a huge amount of investment over the long-term, but its economic benefits have a certain lag. Thus, there is no significant relationship between this indicator and the others in the short-term. 
As the current research illustrates, Lotka-Volterra equations provide a simple model to capture the main characteristics of the dynamic competition between GDP and land transportation in Xinjiang. In reality, however, many additional factors affect the economy and transportation, so it cannot capture all the possible relationships. Future research should apply the LV-COMSUD framework to develop more parameters and comparisons in different research areas; the results should be helpful in transportation planning.

Acknowledgments: We sincerely thank Lv Guanghui for his assistance in the revision of this manuscript. This work is financially supported by Highway Industry Standard Project "Desert Highway Road Design and Construction Guide" by Ministry of Transport of the People's Republic of China (JTG-201514) and "China-Kazakhstan" Silk Road Economic Belt, Science and Technology Cooperation Project for Developing Countries, "Technical Cooperation in Ecological Wall Construction in Emerging Cities" by Ministry of Science and Technology of the People's Republic of China (No. KY201502003).

Author Contributions: Jingxin Sun, Zhinong Li, Jiaqiang Lei, DexiongTeng and Shengyu Li conceived and designed this study; Jingxin Sun and Dexiong Teng analyzed the data; Jingxin Sun wrote the paper.

Conflicts of Interest: The authors declare no conflict of interest.

\section{References}

1. Yang, Z.S.; Fan, J.M. Transportation and Economic Development. Econ. Issues 1995, 8, 42-43.

2. Lu, D.D. The Theory and Practice of China's Regional Development, 1st ed.; Science Press: Beijing, China, 2003; pp. 221-222. ISBN 9787030112040.

3. Edward, J.T.; Howard, L.G. Geography of Transportation, 2nd ed.; Prentice Hall: Upper Saddle River, NJ, USA, 1996; pp. 38-43. ISBN 0133685721.

4. Liu, J.Q.; He, J.H. An Empirical Study on the Development of Transportation Industry and National Economy. J. Transp. Syst. Eng. 2002, 2, 82-86.

5. Garcia, M.T.; McGuire, T.J.; Porter, R.H. The effect of public capital in state level production functions reconsidered. Rev. Econ. Stat. 1996, 78, 177-180. [CrossRef]

6. Holtz, E.D.; Schwarz, A.E. Spatial productivity spillovers from public infrastructure: Evidence from state highways. Int. Tax Public Financ. 1995, 2, 459-468. [CrossRef]

7. Mehmet, A.B.; Müge, K.; Hakan, Y. Granger-causality between transportation and GDP: A panel data approach. Transp. Res. Part A 2014, 63, 43-55.

8. Michael, I.; David, L. Mutual causality in road network growth and economic development. Transp. Policy 2016, 45, 209-217.

9. Kveiborg, O.; Fosgerau, M. Decomposing the decoupling of Danish road freight traffic growth and economic growth. Transp. Policy 2007, 14, 39-48. [CrossRef]

10. Li, Y.C.; Zhao, L.; Suo, J.J. Comprehensive Assessment on Sustainable Development of Highway Transportation Capacity Based on Entropy Weight and TOPSIS. Sustainability 2014, 6, 4685-4693. [CrossRef]

11. Feng, H. An Analysis of the Contribution of Highway Traffic to Xinjiang's National Economic Growth. Master's Thesis, Shanghai Maritime University, Shanghai, China, 2005.

12. $\mathrm{Xu}, \mathrm{C} . \mathrm{F}$. Research of the Relationship between Highway Traffic and the Development of Economy and Society in Xinjiang Production and Construction Corps. Ph.D. Thesis, Wuhan University of Technology, Wuhan, China, 2011.

13. Zhu, Y.N. Research on the relationship between regional transport and regional economic in southern Xinjiang. Master's Thesis, Beijing Jiaotong University, Beijing, China, 2011.

14. Zhang, L.; Zhang, X.L.; Du, H.R.; Ni, T.Q. The Different Impact of Passenger Traffic Way son the Different Economic Growth in Xinjiang Region. J. Chongqing Norm. Univ. (Nat. Sci.) 2016, 33, 211-216.

15. Lotka, A.J. Elements of Physical Biology, 1st ed.; Williams \& Wilkins Co.: Baltimore, MA, USA, 1925.

16. Volterra, V. Leconssur la Theoriemathematique de la Lutte Pour la vie; Gauthier-Villars: Paris, France, 1931.

17. Wang, X.W. Analysis on application effect of Xinjiang Highway Transportation 11th Five-year Plan. Master's Thesis, Changan University, Xi'an, China, 2010.

18. Development Plan of "13th Five-Year Plan" of Transportation in Xinjiang Uygur Autonomous Region. Available online: http:/ / www.xjjt.gov.cn/article/2015-11-23/art84330.html (accessed on 3 July 2015).

19. Box, G.E.P.; Jenkins, G.M. Time Series Analysis: Forecasting and Control; Holden-Day: San Francisco, CA, USA, 1976. 
20. Lewis, C.D. Industrial and Business Forecasting Methods: A Practical Guide to Exponential Smoothing and Curve Fitting; Butter-Worth-Heinemann: London, UK, 1982.

21. Girifalco, L.A. Dynamics of Technological Change, 1st ed.; Van Nostrand Reinhold: New York, NY, USA, 1991; ISBN 978-1-4684-6511-2.

22. Liu, P.Z.; Gopalsamy, K. On a model of competition in periodic environments. Appl. Math. Comput. 1997, 82, 207-238. [CrossRef]

23. Pistorius, C.W.I.; Utterback, J.M. A Lotka-Volterra Model for Multi-Mode Technological Interaction: Modelling Competition, Symbiosis and Predator Prey Modes; Working Papers; Massachusetts Institute of Technology (MIT), Sloan School of Management: Cambridge, MA, USA, 1996; pp. 3929-3996.

24. Hart, T. Transport Investment and Disadvantage Regions: UK and European policies since the 1950s. Urban Stud. 1993, 30, 417-435. [CrossRef]

25. Banister, D. Transport Planning in the UK, USA and Europe, 1st ed.; E \& FN Spon: London, UK, 1994; ISBN 0-419-18930-0.

26. Aschauer, A.D. Is Public Expenditure Productive? J. Monetary Econ. 1988, 23, 177-200. [CrossRef]

27. Munnell, A.H. Why Has Productivity Growth Declined? Productivity and Public Investment. N. Engl. Econ. J. Rev. 1990, 30, 3-22.

28. Durkin, J.T., Jr.; Wassmer, R.W. Public Infrastructure Spending and Private Generation in Large US Cities; Working Paper; Lincoln Institute of Land Policy: Cambridge, MA, USA, 1994.

29. Holtz-Eakin, D.; Schwartz, A.E. Infrastructure in a Structural Model of Economic Growth. Reg. Sci. Urban Econ. 1994, 25, 131-151. [CrossRef]

30. Botham, R. Regional Development Effects of Road Investment. Transp. Plan. Technol. 1980, 6, 97-108. [CrossRef]

31. Liu, X.T.; Chen, W.J. Dynamics of spatial pattern of county's economics during 2004-2013 in Xinjiang, China. J. Desert Res. 2015, 35, 1089-1095.

(C) 2018 by the authors. Licensee MDPI, Basel, Switzerland. This article is an open access article distributed under the terms and conditions of the Creative Commons Attribution (CC BY) license (http://creativecommons.org/licenses/by/4.0/). 